\title{
Molecular profiles of EGFR, K-ras, c-met, and FGFR in pulmonary pleomorphic carcinoma, a rare lung malignancy
}

\author{
Soohyeon Lee $\cdot$ Youngwook Kim $\cdot$ Jong-Mu Sun $\cdot$ Yoon La Choi \\ Jhin Gook Kim · Young-Mog Shim • Yeon Hee Park · Jin Seok Ahn • \\ Keunchil Park · Jung Ho Han $\cdot$ Myung-Ju Ahn
}

Received: 23 March 2011/Accepted: 12 May 2011/Published online: 28 May 2011

(C) The Author(s) 2011. This article is published with open access at Springerlink.com

\begin{abstract}
Background Pulmonary pleomorphic carcinoma (PPC) is a rare type of lung cancer characterized by the poor response to conventional chemotherapy and subsequent disappointing outcomes. Therefore, it is paramount to delineate the molecular characteristics of this disease entity.

Methods In this study, we retrospectively examined the surgical specimens of 61 patients who underwent lung surgery. Mutational or gene amplification statuses of epidermal growth factor receptor (EGFR), $k$-ras, $c$-kit, $c$-met, and fibroblast growth factor receptor (FGFR) were examined using genomic DNA sequencing, real-time PCR and/ or fluorescence in situ hybridization (FISH).
\end{abstract}

Soohyeon Lee and Youngwook Kim contributed equally to this study.

S. Lee · J.-M. Sun · Y. H. Park · J. S. Ahn · K. Park ·

M.-J. Ahn $(\bowtie)$

Division of Hematology-Oncology, Department of Medicine,

Samsung Medical Center, Sungkyunkwan University School

of Medicine, 50 Irwon-dong Gangnam-gu, Seoul 135-710, Korea

e-mail: silkahn@skku.edu

Y. Kim · K. Park

Medical Nano-element Development Center, Samsung Medical

Center, Sungkyunkwan University School of Medicine,

50 Irwon-dong Gangnam-gu, Seoul 135-710, Korea

Y. L. Choi · J. H. Han

Department of Pathology, Samsung Medical Center,

Sungkyunkwan University School of Medicine,

50 Irwon-dong Gangnam-gu, Seoul 135-710, Korea

J. G. Kim · Y.-M. Shim

Department of Thoracic Surgery, Samsung Medical Center,

Sungkyunkwan University School of Medicine,

50 Irwon-dong Gangnam-gu, Seoul 135-710, Korea
Results The median age was 61 years, and 50 patients were men and 11 were women. In the histologic review of epithelial component, adenocarcinoma were in 44 cases ( $72 \%$ ), squamous cell carcinoma in $15(25 \%)$ and large cell carcinoma in 2 patients (3\%). Overall, 30 cases (49\%) had any molecular alterations. Nine patients $(15 \%)$ possessed EGFR deletion in exon $19(n=8)$ or L858R mutations in exon 21 $(n=1)$, while 3 other cases having atypical EGFR mutations. Six patients $(9.8 \%$ ) had $k$-ras mutations in exon 12 , and 3 had $c$-kit mutations. High gene copy number of $c$-met was found in 11 patients (18.0\%) and that of FGFR was in 6 patients $(9.8 \%)$. No significant relationships were identified among the occurrence and type of mutations and patient survival or any other clinicopathological variables.

Conclusions Given the diverse repertoire of mutational profiles observed in PPC samples, clinical trials based on accurate cancer-genotyping should be considered as a legitimate treatment scheme for this rare disease entity in the future.

Keywords Lung cancer - Pulmonary pleomorphic carcinoma $\cdot$ EGFR $\cdot \mathrm{k}$-ras $\cdot \mathrm{c}$-kit $\cdot \mathrm{c}$-met $\cdot$ FGFR

\section{Background}

Pulmonary pleomorphic carcinoma (PPC) is a rare pulmonary epithelial malignant tumor that represents $0.1-0.4 \%$ of all malignant tumors of the lung (Ito et al. 2010; Pelosi et al. 2010). According to the World Health Organization's classification of lung tumors, PPC is a group of poorly differentiated tumors characterized pathologically by a combination of epithelial and mesenchymal elements and is defined as either non-small-cell carcinoma combined with at least $10 \%$ of neoplastic spindle or giant cell (Beasley et al. 2005). 
The clinical characteristics and the behaviors of these tumors have not been well known due to a small series of data. In general, however, PPC has been reported to occur predominantly in men who smoke heavily, with an average age at diagnosis of 60 years, and is characterized by the poor response to conventional chemotherapy and subsequent disappointing clinical outcomes (Bae et al. 2007; Fishback et al. 1994; Hong et al. 2009; Mochizuki et al. 2008; Rossi et al. 2003).

Compared with other common epithelial cancers, current knowledge about the biology of PPC is very limited, and as a result, little is known about its molecular pathology. Some genetic alterations appear frequently in nonsmall-cell lung cancer and drugs targeting these genetic pathways are clinically available. Some selected genes, such as epidermal growth factor receptor (EGFR), $k$-ras, $p 53$, etc., have been analyzed in small cohorts of PPC patients (Arita et al. 2005; Blaukovitsch et al. 2006; Italiano et al. 2009; Kaira et al. 2010; Pelosi et al. 2004; Ushiki et al. 2009). A previous study reported that EGFR mutation was positive in about $20 \%$ of PPC, which give some chance to apply target agents to PPC (Kaira et al. 2010). To date, however, extensive molecular researches on PPC have been largely hampered by the rarity of the tumor and a lack of established cell lines and animal models.

To gain more extensive insights into the oncogenic nature of PPC, we have characterized the mutational or amplification status of several well-known oncogenic target genes, such as EGFR mutation, $K$-ras mutation, c-kit mutation, c-met amplification, and fibroblast growth factor receptor (FGFR) amplification in 61 surgically resected PPC samples. The target genes were selected based on the possibility that these are the most frequent genes in NSCLC and are correlated with clinical outcomes of available target agents (Han et al. 2006; Heinrich et al. 2002; Ma et al. 2003; Noble et al. 2004).

\section{Materials and methods}

\section{Patient samples}

Tumors specimens from 61 patients with PPC who underwent surgical resection at Samsung Medical Center from January 1995 to March 2009 were identified. All tumors were retrieved from paraffin-embedded blocks. All slides from the lung resection specimens were reviewed by two expert pathologists (JHH and YLC). In all cases, the diagnosis of PPC was established according to the 2004 World Health Organization's classification of tumors. Clinical staging was determined according to the 6th International Association for the Study of Lung Cancer.
Biomarker analysis

Biomarker analyses were retrospectively performed on formalin fixed paraffin-embedded (FFPE) archival tumor tissues after pathologic review. Sections from tissue blocks containing more than $80 \%$ representative malignant cells were used for all analyses.

The mutational analyses of EGFR (exon 18-21), $k$-ras (exon 2, 3), and c-kit (exon 9, 11, 13, and 17) were performed using directional sequencing of PCR fragments amplified from genomic DNA. The results were marked as mutation-positive if a mutation was detected in both the forward and reverse DNA strand.

Gene copy numbers of $c$-met per cell were determined using fluorescence in situ hybridization (FISH) with the Kreathech Poseidon MET/SE 17-probe kit. Copy numbers of FGFR were determined using bacterial artificial chromosome clones \#669(10q26.13) and \#493(10q26.13) containing FGFR $_{2}$ (Macrogen, Seoul, Korea) labeled with rhodamine fluorescent dye. The centromere clones labeled with FITC fluorescent dye were \#5331, \#5344, and \#46 (10q12.1). Briefly, for FISH procedures, $4-\mu \mathrm{m}$-thick sections of FFPE tissue blocks were deparaffinized, dehydrated, and immersed in $0.2 \mathrm{~N} \mathrm{HCl}$, and then boiled in a microwave in citrate buffer ( $\mathrm{pH}$ 6.0). The probe mixtures were added to the slides, and then the slides were incubated in a humidified atmosphere at $73^{\circ} \mathrm{C}$ for $5 \mathrm{~min}$ to denature the probe and target DNA, after which they were sequentially cooled and incubated at $37^{\circ} \mathrm{C}$ for $19 \mathrm{~h}$ to allow for hybridization. The slides were then washed with $0.4 \times \mathrm{SSc} / 0.3 \% \mathrm{NP}-40$ for $2 \mathrm{~min}$ at room temperature, followed by $2 \times \mathrm{SSc} / 0.1 \% \mathrm{NP}-$ 40 for $5 \mathrm{~min}$ at $73^{\circ} \mathrm{C}$. For the nuclei counterstaining, 4,6diamidini-2-phenylindone (DAPI) and anti-face compound (p-phenylenediamine) were added. Signals for each probe were evaluated under a microscope equipped with a triplepass filter (DAPI/Green/Orange; Vysis). At least 100 tumor cell nuclei were counted per case. FISH analysis was performed independently by two pathologists who were blinded to the patients' clinical characteristics and to all other molecular variables.

High gene copy number was defined as high polysomy ( $\geq$ cutoff copies in $>40 \%$ of cells using Colorado system) or gene amplification (presence of tight gene clusters; a gene: chromosome ratio per cell $\geq 2$ or $\geq 15$ copies of target probes per cell in $\geq 10 \%$ of cells analyzed).

All biomarkers were independently determined with blinding to clinical outcome prior to any statistical analysis.

Statistical methods

All patients were included in the statistical calculations. Follow-up was obtained in all cases and was ended on 
November 1, 2009. Categorical variables were compared using the Chi-squared test. The overall survival (OS) was the interval from lung surgery to death or the last followup. Survival was assessed using the Kaplan-Meier method. Results were considered significant at the 0.05 level. Statistical analyses were performed using the SPSS software program, version 18.0.

\section{Results}

Patient characteristics and survival

A total of 61 PPC specimens were available, and the clinical characteristics of patients are described in Table 1. The median age was 61.4 years (range, 36.0-85.0 years), and the male $(n=50) /$ female $(n=11)$ ratio was 5:1.

Table 1 Patients' characteristics $(N=61)$

\begin{tabular}{ll}
\hline & Number of patients $(\%)$ \\
\hline Median age, years (range) & $61.4(36.0-85.0)$ \\
Sex & \\
Male & $50(82.0)$ \\
Female & $11(18.0)$ \\
Smoking status & \\
Never smoker & $21(34.4)$ \\
Ex-smoker & $27(44.2)$ \\
Current smoker & $13(21.3)$ \\
Performance status (ECOG) & \\
0 & $29(47.5)$ \\
1 & $29(47.5)$ \\
2 & $3(4.9)$ \\
Adjuvant chemotherapy & $14(23.0)$ \\
Adjuvant radiotherapy & $10(16.4)$ \\
Surgery type & \\
Pneumonectomy & $5(8.2)$ \\
Bilobectomy & $10(16.4)$ \\
Lobectomy & $43(70.5)$ \\
Others & $3(4.9)$ \\
Stage & $33.9(0.0-69.3)$ \\
I & $26(41.1)$ \\
III & $19(31.1)$ \\
IV & $39(21.3)$ \\
Yecurrence & \\
Nes & \\
\hline
\end{tabular}

Thirteen patients were current smokers, 27 patients were ex-smokers, and 21 had never been smokers. Tumor size ranged between 14 and $153 \mathrm{~mm}$ (median, $46 \mathrm{~mm}$ ).

All patients underwent curative resection except three patients who received palliative surgery for metastatic disease. Pathological stages were stage I in 26 patients (41.0\%), stage II in 19 (31.1\%), stage III in $13(21.3 \%)$, and stage IV in 3 patients. The median survival time was 33.9 months (95\% CI, 0.0-69.3 months).

Of the 61 patients, $22(36 \%)$ relapsed after surgery with 16 recurrences in distant sites. The other 39 patients $(63.9 \%)$ experienced no recurrence at the time of analysis, including 11 patients who died of non-cancer-related disease (pneumonia, heart disease, etc.).

Among the various clinical parameters, univariate analyses indicated that early disease stage $(P<0.001)$, good ECOG performance status $(P<0.001)$, and receipt of adjuvant radiotherapy $(P=0.012)$ or palliative chemotherapy $(P<0.001)$ were related with significantly increased OS. The multivariate analysis showed that clinical parameters including stage, ECOG performance status, and receipt of palliative chemotherapy were independent prognostic factors in terms of OS (Table 2).

Epithelial/mesenchymal components and survival

In the histologic review of malignant epithelial components, adenocarcinoma were in 44 cases (72\%), squamous cell carcinoma in $15(25 \%)$, and large cell carcinoma in 2 patients $(3 \%)$. For the mesenchymal components, 44 cases $(72 \%)$ had spindle cell tumors and $17(28 \%)$ had giant cell tumors. Therefore, 5 subgroups were categorized according to the epithelial/mesenchymal component: adenocarcinoma/spindle cell tumors were in 29 cases $(48 \%)$, adenocarcinoma/giant cell tumors in 15 (25\%), squamous cell carcinoma/spindle cell tumors in $13(21 \%)$, squamous cell carcinoma/giant cell tumors in $2(3 \%)$, and large cell carcinoma/spindle cell tumors in 2 cases $(3 \%)$.

The median OS in patients with adenocarcinoma ( $n=44)$ and non-adenocarcinoma $(n=17)$ component were 30.2 months $(95 \%$ CI, $0.0-70.8$ months $)$ and 33.9 month (95\% CI, 13.2-54.6 months), respectively, and there was no statistical difference $(P=0.86)$. Patients with spindle cell tumor component $(n=44)$ showed longer median OS (38.9 months: 95\% CI cannot be calculated) than those with giant cell tumor component (24.7 months: 95\% CI, 5.9-43.5 months), but the difference was short of the statistical significance $(P=0.37)$. In the analyses of 5 subgroups categorized by the epithelial/mesenchymal component, there was no significant survival difference among 5 subgroups (data not shown). 
Table 2 Univariate and multivariate analysis for overall survival

\begin{tabular}{|c|c|c|c|c|c|c|}
\hline \multirow[t]{2}{*}{ Variables } & \multicolumn{3}{|c|}{ Univariate analysis } & \multicolumn{3}{|c|}{ Multivariate analysis } \\
\hline & Survival (mon) & $95 \% \mathrm{CI}$ & $P$-value & Survival (mon) & $95 \% \mathrm{CI}$ & $P$-value \\
\hline \multicolumn{7}{|l|}{ Age } \\
\hline$<61.4$ & NA & NA & 0.157 & & & \\
\hline$\geq 61.4$ & 30.2 & $9.3-51.2$ & & & & \\
\hline \multicolumn{7}{|l|}{ Sex } \\
\hline Male & 38.9 & $7.8-70.1$ & 0.462 & & & \\
\hline Female & 18.0 & $1.6-34.4$ & & & & \\
\hline \multicolumn{7}{|l|}{ Smoking } \\
\hline Never smoker & 18.0 & $0.0-37.0$ & 0.163 & & & \\
\hline Ex-smoker & NA & NA & & & & \\
\hline Current smoker & 38.9 & $0.0-84.8$ & & & & \\
\hline \multicolumn{7}{|c|}{ Performance status (ECOG) } \\
\hline 0 & NA & NA & $<0.001$ & 2.586 & $1.304-5.128$ & 0.007 \\
\hline 1 & 24.7 & $13.5-35.9$ & & & & \\
\hline 2 & 2.4 & $1.9-2.8$ & & & & \\
\hline \multicolumn{7}{|c|}{ Adjuvant chemotherapy } \\
\hline No & 30.2 & $14.4-46.1$ & 0.642 & & & \\
\hline Yes & NA & NA & & & & \\
\hline \multicolumn{7}{|c|}{ Adjuvant radiotherapy } \\
\hline No & 94.7 & $14.2-175.1$ & 0.012 & & & \\
\hline Yes & 9.5 & $4.1-14.9$ & & & & \\
\hline \multicolumn{7}{|l|}{ Surgery } \\
\hline Pneumonectomy & 18.1 & $0.0-43.1$ & 0.218 & & & \\
\hline Bilobectomy & 12.0 & $0.0-27.7$ & & & & \\
\hline Lobectomy & 94.7 & $12.2-177.1$ & & & & \\
\hline Others & NA & NA & & & & \\
\hline \multicolumn{7}{|l|}{ Stage } \\
\hline 1 & NA & NA & $<0.001$ & 1.577 & $1.100-2.261$ & 0.013 \\
\hline 2 & 33.9 & $17.9-49.9$ & & & & \\
\hline 3 & 7.8 & $0.0-15.5$ & & & & \\
\hline 4 & 8.9 & $4.9-12.9$ & & & & \\
\hline \multicolumn{7}{|l|}{ Recurrence } \\
\hline No & 94.7 & NA & $<0.001$ & & & \\
\hline Yes & 12.0 & $2.3-21.7$ & & & & \\
\hline \multicolumn{7}{|c|}{ Palliative chemotherapy } \\
\hline No & 94.7 & $0.9-188.5$ & $<0.001$ & 0.393 & $0.173-0.859$ & 0.020 \\
\hline Yes & 9.5 & $3.9-15.2$ & & & & \\
\hline
\end{tabular}

Molecular profiles and survival

Of the 61 clinical tumor specimens profiled, 30 cases contained any genetic mutations or increased gene dosages. The molecular profiles, combined with the histologic review of epithelial/mesenchymal components and smoking status, of these 30 cases were shown in Table 3.

Somatic EGFR mutations were found in 12 out of 61 patients $(19.6 \%)$. Nine patients $(14.8 \%)$ possessed well- established activating EGFR mutation signatures, with exon 19 partial deletions in 8 patients and an exon 21 L858R substitution mutation in one patient. The other three mutations resided in either exon 20 or exon 21 , the targetabilities by clinically available EGFR inhibitors of which are currently not well established. From the profiling analysis of the tumor specimens, we identified 6 patients who possessed k-ras mutations. A heterozygous $\mathrm{G}$ to $\mathrm{T}$ substitution at nucleotide position 34 (Gly to Cys) was 
Table 3 Molecular profiles in PPCs $(N=30)$

\begin{tabular}{|c|c|c|c|c|c|}
\hline $\begin{array}{l}\text { Sample } \\
\text { No }\end{array}$ & EGFR & KRAS & c-kit & c-met & FGFR \\
\hline 2 & & & & High polysomy & \\
\hline 4 & & & & High polysomy & \\
\hline 7 & Exon 19 c.2240-2257del & & Exon 9 p.Thr488Ala & & \\
\hline 8 & Exon 19 c.2240-2257del & & & & \\
\hline 9 & & & & High polysomy & \\
\hline 11 & Exon 21 p.Leu858Arg & & & & \\
\hline 15 & Exon 19c.2240-2257del & & & & \\
\hline & Exon 21 c.2561insC & & High polysomy & & \\
\hline 16 & & & & High polysomy & \\
\hline 17 & & & & High polysomy & \\
\hline 21 & & & & High polysomy & \\
\hline 25 & & c.35G > T;p.Gly12Val & & & \\
\hline 26 & Exon 20 p.Arg776Cys & & & High polysomy & \\
\hline 28 & & c.34G > T;p.Gly12Cys & & & \\
\hline 32 & & c.34G > T;p.Gly12Cys & & & \\
\hline 34 & $\begin{array}{r}\text { Exon } 20 \text { c.2370_2371insAG, } \\
\text { c.2298G > C(p.Ala800Pro) }\end{array}$ & & & & \\
\hline 36 & Exon 19 c.2240-2257del & c.35G > A;p.Gly12Asp & & & + \\
\hline 37 & Exon 19 c.2240-2257del & & & & \\
\hline 38 & & & & High polysomy & \\
\hline 40 & & & & High polysomy & \\
\hline 41 & & c.35G > C;p.Gly12Ala & & & \\
\hline 42 & Exon 19 c.2240-2257del & & $\begin{array}{l}\text { Exon } 9 \text { p.Pro468Leu, } \\
\text { p.Val489Asp }\end{array}$ & & + \\
\hline 46 & & & & & + \\
\hline 47 & Exon 19 c.2240-2257del & & $\begin{array}{l}\text { Exon } 9 \\
\text { p.Phe483Leu,p.Cys491Arg }\end{array}$ & & \\
\hline 50 & Exon 19 c. $2240-2257 \mathrm{del}$ & & & & \\
\hline 51 & & & & & + \\
\hline 52 & & c.34G > T;p.Gly12Cys & & & \\
\hline 55 & $\begin{array}{l}\text { Exon } 20 \\
\text { p.Ser768_Asp770dupSerValAsp }\end{array}$ & & & & \\
\hline 58 & & & & Amplification & \\
\hline 59 & & & & & + \\
\hline 60 & & & & & + \\
\hline
\end{tabular}

found in 3 patients. The other three mutations also corresponded to the $k$-ras amino acid 12 substitution mutation, including a heterozygous $\mathrm{G}$ to $\mathrm{T}$ substitution at nucleotide position 35 (Gly to Val), a G to A substitution at 35 (Gly to Asp), and a $\mathrm{G}$ to $\mathrm{C}$ substitution at 35 (Gly to Ala). Interestingly, one patient (patient number 36) with k-ras mutation (c.35G>;p Gly12Ala) also had EGFR mutation (exon 19 deletion). In the analysis of $c$-kit, we identified 3 patients who possessed $c$-kit mutations.

Further, we analyzed the gene dosage statuses of FGFR and $c$-met using fluorescence in situ hybridization (FISH).
The median gene dosage of FGFR was 1.06 (range, $0.33-5.76)$, and, with the cutoff value set at 2 points, six patients showed increased FGFR gene dosage (Fig. 1). In the case of $c$-met, 11 patients demonstrated increased gene dosage; $c$-met amplification was observed in one patient and high polysomy was seen in 10 patients (Fig. 2). There was no statistically significant correlation between high gene copy number of the $c$-met gene and patient survival.

There were no statistically significant correlations between the type of gene mutations and overall survival (Table 4). 
Fig. 1 Fluorescence in situ hybridization (FISH) assay for the detection of the FGFR a No amplification of the FGFR b Amplification of the FGFR
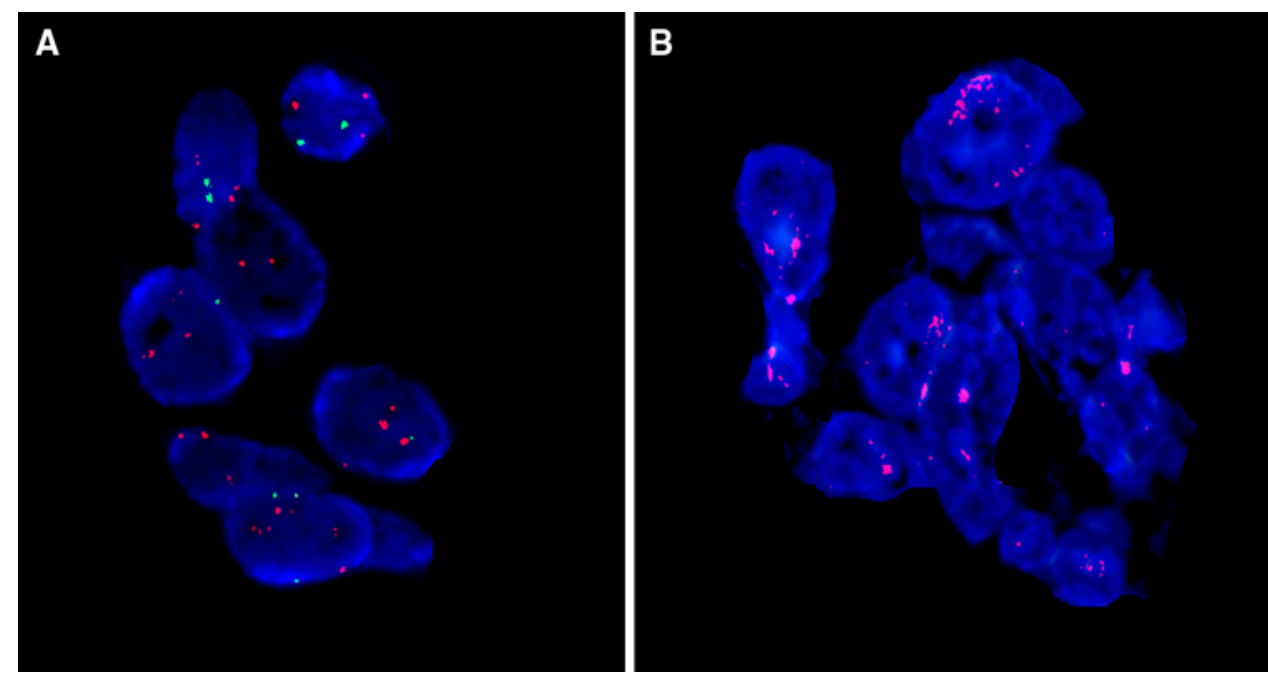

Fig. 2 FISH assay for the detection of c-Met a No amplification of the c-Met b High polysomy of the c-met
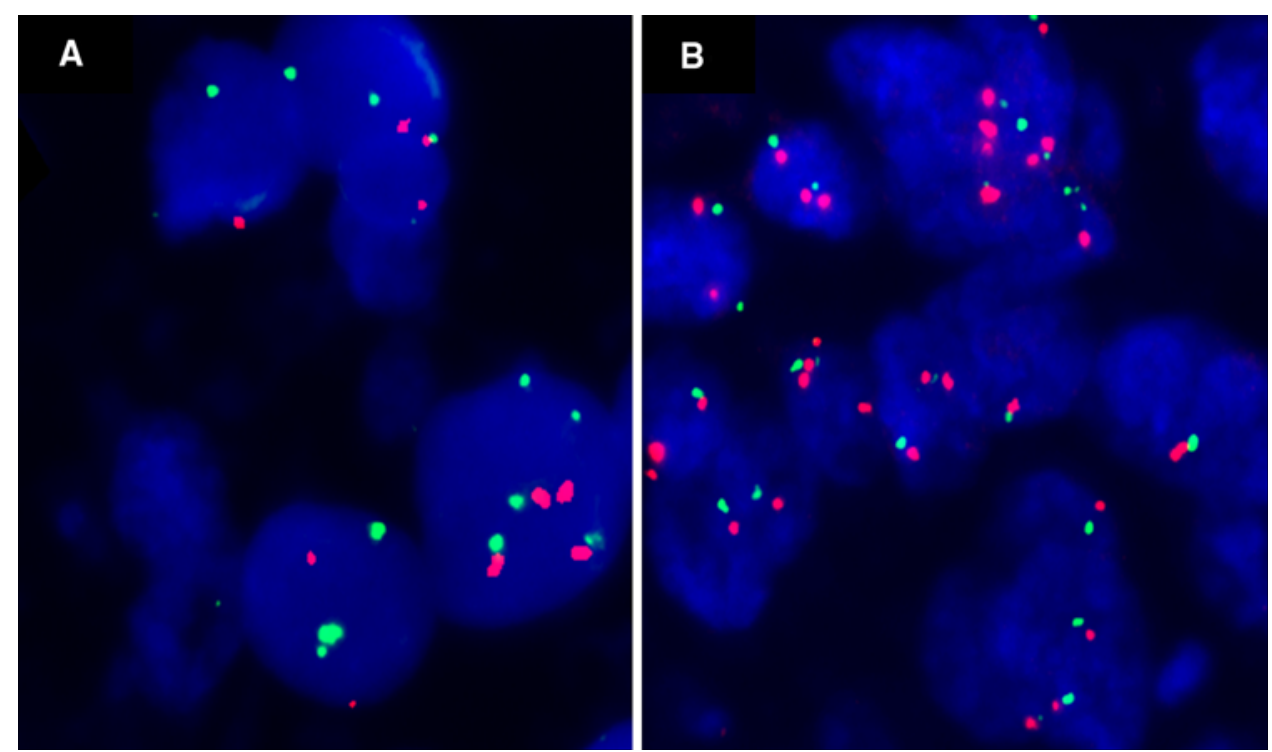

The distribution of activating EGFR mutation

in association with clinicopathologic factors

Of 44 tumors with adenocarcinoma components, 6 (13.6\%) had activating EGFR mutations, and $3(17.6 \%)$ of 17 tumors with non-adenocarcinoma component had activating EGFR mutations. Therefore, the distribution of activating EGFR mutation was not associated with the type of malignant epithelial components $(P=0.69)$. The distribution of activating EGFR mutation was also insignificantly associated with other clinicopathologic factors, such as gender (all 9 in men, $P=0.13$ ), smoking status (nevervs ever-smoker, $P=0.94$ ), and the type of mesenchymal malignant components (spindle cell vs giant cell, $P=0.23)$.

\section{Discussion}

PPC is a rare aggressive disease characterized by a high rate of distant recurrence after initial surgery for localized disease (Hong et al. 2009). There is presently no available data indicating the optimal management of patients with this advanced disease. In particular, the role of chemotherapy remains unclear, and these patients are often treated according to the results of trials of enrolled patients with NSCLC, such as squamous cell carcinoma or adenocarcinoma. Many targeted agents are widely used for the treatment of patients with advanced NSCLC. However, whether these drugs have some activity in PPC is not yet clear.

EGFR, K-ras, c-met, and FGFR are receptor tyrosine kinases (RTKs) frequently activated by gene amplification 
Table 4 Association of EGFR, KRAS, c-kit, C-met, and FGFR mutations with overall survival using univariate analysis

\begin{tabular}{llll}
\hline Molecular markers & \multicolumn{3}{l}{ Univariate analysis } \\
\cline { 2 - 4 } & Survival (months) & $95 \%$ CI & $P$-value \\
\hline EGFR & 30.2 & $0.0-70.1$ & 0.879 \\
No & 33.9 & NA & \\
Yes & & & \\
k-ras & 33.9 & $0.0-71.4$ & 0.348 \\
No & 10.1 & $0.0-26.8$ & \\
Yes & & & \\
c-kit & 30.2 & $13.6-46.8$ & 0.575 \\
No & NA & NA & \\
Yes & & & \\
FGFR & 33.9 & $0.0-72.3$ & 0.744 \\
No & 10.1 & NA & \\
Yes & & & \\
c-Met & 26.0 & $9.2-42.8$ & 0.374 \\
No & 94.7 & $12.0-177.3$ & \\
Yes & &
\end{tabular}

or mutation in a variety of human neoplasm especially lung cancer. EGRF and K-ras have been already well-known target genes in NSCLC. The occurrence of MET amplification and EGFR/K-ras mutation might be mutually exclusive suggesting several distinct mechanisms in the development of NSCLC (Onitsuka et al. 2010). FGFRmediated signals in cooperation with those transmitted by EGFR are involved in growth and survival of human NSCLC cells and should be considered as targets for combined therapeutic approaches (Fischer et al. 2008). Various RTKs have come into the focus of therapeutic considerations since they can be targeted by pharmaceutical intervention and because tumors bearing oncogenic RTK mutations generally show a good response to targeted therapy.

To gain further insight into the clinical targetabilities of PPCs, we performed a molecular analysis of 61 resected PPCs. Previous studies have analyzed only a small number of tumors and have mostly focused on histological and clinical characteristics of this rare disease entity. Thus, this study is one of the first attempts to genetically characterize PPCs, with the underlying premise of rapidly extending this knowledge to clinical oncology practices. Several characteristics of PPCs emerged from these analyses. Mutational analysis of PPCs demonstrated that about half of the patients possess one or multiple combinations of the above five genetic abnormalities. The activating EGFR mutations were seen in 9 patients (14.8\%) (19.8\%, including 3 atypical mutations), whereas $k$-ras oncogenic mutations were identified in six patients (9.8\%); the EGFR positive rates is largely consistent with that observed for other lung cancers in East Asians (Ahn et al. 2008), and with the recently evaluated value $(18 \%, 3$ out of 17$)$ in Japanese PPC patients (Kaira et al. 2010). However, the mutation rate found here is in contrast to results of Italiano et al., who reported that PPCs are characterized by a lack of EGFR mutation and a high rate of $k$-ras mutations (Italiano et al. 2009; Pelosi et al. 2004). It is well established that ethnic differences heavily affect EGFR etiology in lung cancer, and PPCs might be under similar ethnic influences in their ontogeny. In the present study, however, the distribution of EGFR mutation was not in line with the wellestablished phenomena. Namely, the EGFR mutations were detected, irrespective of clinicopathologic factors such as the component of adenocarcinoma, smoking status, and gender. Although this distribution of EGFR mutation can be explained in part by the specific characteristics of PPC, it should be cautious to interpret these data due to the small number of samples.

In the case of $c$-met, 11 patients demonstrated increased gene dosage; a $c$-met amplification and 10 high polysomies were detected using FISH. The c-met receptor tyrosine kinase has been associated with NSCLC as well as with SCLC (Chang et al. 2001; Jagadeeswaran et al. 2007; Maulik et al. 2002), suggesting that the $c$-met receptor may play an important role in cellular fate changes, including the epithelial to mesenchymal transition (Kubo et al. 2009; Salgia 2009). Increased $c$-met gene dosage was observed to be largely independent of EGFR and $k$-ras mutations in PPCs, positioning its blockade as an interesting monotherapy target.

Remarkably, the five genetic factors we have chosen to study in the analysis resulted in an unexpectedly high ratio of PPC samples detected with this defined probe set of genetic alterations. The fact that these patients who possess druggable or actionable molecular targets should be considered as candidates for mono or combinational targeted cancer therapy leads to an immediate clinical implication that warrants further validation in prospective clinical trials. Especially, EGFR mutation can be a possible predicitive marker for gefitinib or erlotinib and it is important to investigate where EGFR-TKI is effective for advanced PPC patients.

The molecular origin of PPC still remains largely obscure. It is the definition of a disease unit based on the histological observation, and whether there exists a singular genetic event leading to the emergence of this rare tumor type is still unknown. It is possible that a minute proportion of non-small-cell lung cancer will undergo a series of secondary genetic changes during the course of tumor evolution, reprogramming the cellular fates of primary tumors and propelling rare transitions in cellular fate through transdifferentiation or dedifferentiation. This redirected cellular fate specification may culminate in 
histologically mixed cell populations observed in patient samples. The mutation profiling study presented here indicates that, at least, the oncogenic origins of this cancer type may be rather diverse, encompassing several wellknown pulmonary oncogenic genetic factors.

The limitation of this study, as with many other mutation profiling studies, is that we can only detect a set of mutations in a subset of oncogenes with preestablished oncogenecity. Thus, other sets of mutations critical to the oncogenic process of PPCs might be missing in the analysis. Moreover, the percentages of these mutations detected from this preliminary screening that correspond to oncogenic or driver mutations need to be determined in future prospective studies. Given the rarity of this disease type, it will take a significant amount of time to accumulate sufficient clinical cases to properly determine the benefit the patients will experience from prospective oncogeno-chemo trials compared with that of histology-based conventional chemotherapeutics. To resolve this issue, further systemic and hypothesis-driven or a priori knowledge-free genomicsguided patient stratification is warranted in the laboratory to help more accurately describe each patient's onco-genetics map. Until then, however, this preliminary attempt to characterize the mutational space of PPCs, previously thought to be an extremely malignant cancer type, will provide measurable molecular guidance to the alternative molecular treatment of this rare disease.

In summary, we have characterized the mutational statuses of several well-known oncogenic targets in a large set of PPC tumors. Given the diverse repertoire of mutational profiles observed from PPC samples, clinical trials based on accurate cancer-genotyping should be considered as a legitimate treatment scheme for this rare and hard-to-cure disease entity.

Acknowledgments We thank members of the laboratory for their helpful comments and inputs. This work was supported by a grant of the Korea Healthcare technology R\&D Project, Ministry for Health \& Welfare Affairs, Republic of Korea. (A092255) and Samsung Biomedical Research Institute, Seoul, Korea, grant C-H1-103.

Conflict of interest None declared.

Open Access This article is distributed under the terms of the Creative Commons Attribution Noncommercial License which permits any noncommercial use, distribution, and reproduction in any medium, provided the original author(s) and source are credited.

\section{References}

Ahn MJ, Park BB, Ahn JS, Kim SW, Kim HT, Lee JS, Kang JH, Cho JY, Song HS, Park SH, Sohn CH, Shin SW, Choi JH, Ki CS, Park CK, Holmes AJ, Janne PA, Park K (2008) Are there any ethnic differences in molecular predictors of erlotinib efficacy in advanced non-small cell lung cancer? Clin Cancer Res 14:3860-3866

Arita N, Mikami Y, Yoshida M, Konishi I, Horiike N, Miyauchi K, Miyazaki T, Nose M, Ono M (2005) Pleomorphic carcinoma of the lung associated with loss of heterozygosity of p53 gene. Tohoku J Exp Med 206:181-185

Bae HM, Min HS, Lee SH, Kim DW, Chung DH, Lee JS, Kim YW, Heo DS (2007) Palliative chemotherapy for pulmonary pleomorphic carcinoma. Lung Cancer 58:112-115

Beasley MB, Brambilla E, Travis WD (2005) The 2004 world health organization classification of lung tumors. Semin Roentgenol 40:90-97

Blaukovitsch M, Halbwedl I, Kothmaier H, Gogg-Kammerer M, Popper HH (2006) Sarcomatoid carcinomas of the lung-are these histogenetically heterogeneous tumors? Virchows Arch 449:455-461

Chang YL, Lee YC, Shih JY, Wu CT (2001) Pulmonary pleomorphic (spindle) cell carcinoma: peculiar clinicopathologic manifestations different from ordinary non-small cell carcinoma. Lung Cancer 34:91-97

Fischer H, Taylor N, Allerstorfer S, Grusch M, Sonvilla G, Holzmann $\mathrm{K}$, Setinek U, Elbling L, Cantonati H, Grasl-Kraupp B, Gauglhofer C, Marian B, Micksche M, Berger W (2008) Fibroblast growth factor receptor-mediated signals contribute to the malignant phenotype of non-small cell lung cancer cells: therapeutic implications and synergism with epidermal growth factor receptor inhibition. Mol Cancer Ther 7:3408-3419

Fishback NF, Travis WD, Moran CA, Guinee DG Jr, McCarthy WF, Koss MN (1994) Pleomorphic (spindle/giant cell) carcinoma of the lung. A clinicopathologic correlation of 78 cases. Cancer 73:2936-2945

Han SW, Kim TY, Jeon YK, Hwang PG, Im SA, Lee KH, Kim JH, Kim DW, Heo DS, Kim NK, Chung DH, Bang YJ (2006) Optimization of patient selection for gefitinib in non-small cell lung cancer by combined analysis of epidermal growth factor receptor mutation, K-ras mutation, and Akt phosphorylation. Clin Cancer Res 12:2538-2544

Heinrich MC, Blanke CD, Druker BJ, Corless CL (2002) Inhibition of KIT tyrosine kinase activity: a novel molecular approach to the treatment of KIT-positive malignancies. J Clin Oncol 20:1692-1703

Hong JY, Choi MK, Uhm JE, Park MJ, Lee J, Park YH, Ahn JS, Park K, Han JH, Ahn MJ (2009) The role of palliative chemotherapy for advanced pulmonary pleomorphic carcinoma. Med Oncol $26: 287-291$

Italiano A, Cortot AB, Ilie M, Martel-Planche G, Fabas T, Pop D, Mouroux J, Hofman V, Hofman P, Pedeutour F (2009) EGFR and KRAS status of primary sarcomatoid carcinomas of the lung: implications for anti-EGFR treatment of a rare lung malignancy. Int J Cancer 125:2479-2482

Ito K, Oizumi S, Fukumoto S, Harada M, Ishida T, Fujita Y, Harada T, Kojima T, Yokouchi H, Nishimura M (2010) Clinical characteristics of pleomorphic carcinoma of the lung. Lung Cancer 68:204-210

Jagadeeswaran R, Jagadeeswaran S, Bindokas VP, Salgia R (2007) Activation of $\mathrm{HGF} / \mathrm{c}-\mathrm{Met}$ pathway contributes to the reactive oxygen species generation and motility of small cell lung cancer cells. Am J Physiol Lung Cell Mol Physiol 292:L1488-L1494. doi:10.1152/ajplung.00147.2006

Kaira K, Horie Y, Ayabe E, Murakami H, Takahashi T, Tsuya A, Nakamura $Y$, Naito $T$, Endo $M$, Kondo $H$, Nakajima $T$, Yamamoto N (2010) Pulmonary pleomorphic carcinoma: a clinicopathological study including EGFR mutation analysis. J Thorac Oncol 5:460-465

Kubo T, Yamamoto H, Lockwood WW, Valencia I, Soh J, Peyton M, Jida M, Otani H, Fujii T, Ouchida M, Takigawa N, Kiura K, 
Shimizu K, Date H, Minna JD, Varella-Garcia M, Lam WL, Gazdar AF, Toyooka S (2009) MET gene amplification or EGFR mutation activate MET in lung cancers untreated with EGFR tyrosine kinase inhibitors. Int J Cancer 124:1778-1784

Ma PC, Kijima T, Maulik G, Fox EA, Sattler M, Griffin JD, Johnson BE, Salgia R (2003) c-MET mutational analysis in small cell lung cancer: novel juxtamembrane domain mutations regulating cytoskeletal functions. Cancer Res 63:6272-6281

Maulik G, Kijima T, Ma PC, Ghosh SK, Lin J, Shapiro GI, Schaefer E, Tibaldi E, Johnson BE, Salgia R (2002) Modulation of the c-Met/hepatocyte growth factor pathway in small cell lung cancer. Clin Cancer Res 8:620-627

Mochizuki T, Ishii G, Nagai K, Yoshida J, Nishimura M, Mizuno T, Yokose T, Suzuki K, Ochiai A (2008) Pleomorphic carcinoma of the lung: clinicopathologic characteristics of 70 cases. Am J Surg Pathol 32:1727-1735

Noble ME, Endicott JA, Johnson LN (2004) Protein kinase inhibitors: insights into drug design from structure. Science 303:1800-1805

Onitsuka T, Uramoto H, Ono K, Takenoyama M, Hanagiri T, Oyama T, Izumi H, Kohno K, Yasumoto K (2010) Comprehensive molecular analyses of lung adenocarcinoma with regard to the epidermal growth factor receptor, K-ras, MET, and hepatocyte growth factor status. J Thorac Oncol 5:591-596
Pelosi G, Scarpa A, Manzotti M, Veronesi G, Spaggiari L, Fraggetta F, Nappi O, Benini E, Pasini F, Antonello D, Iannucci A, Maisonneuve P, Viale G (2004) K-ras gene mutational analysis supports a monoclonal origin of biphasic pleomorphic carcinoma of the lung. Mod Pathol 17:538-546

Pelosi G, Sonzogni A, De Pas T, Galetta D, Veronesi G, Spaggiari L, Manzotti M, Fumagalli C, Bresaola E, Nappi O, Viale G, Rosai J (2010) Review article: pulmonary sarcomatoid carcinomas: a practical overview. Int J Surg Pathol 18:103-120

Rossi G, Cavazza A, Sturm N, Migaldi M, Facciolongo N, Longo L, Maiorana A, Brambilla E (2003) Pulmonary carcinomas with pleomorphic, sarcomatoid, or sarcomatous elements: a clinicopathologic and immunohistochemical study of 75 cases. Am J Surg Pathol 27:311-324

Salgia R (2009) Role of c-Met in cancer: emphasis on lung cancer. Semin Oncol 36:S52-S58

Ushiki A, Koizumi T, Kobayashi N, Kanda S, Yasuo M, Yamamoto H, Kubo K, Aoyagi D, Nakayama J (2009) Genetic heterogeneity of EGFR mutation in pleomorphic carcinoma of the lung: response to gefitinib and clinical outcome. Jpn J Clin Oncol $39: 267-270$ 